TAO, Vol. 10, No. 4, 777-786, December 1999

\title{
Implications of the Rupture Process from the Displacement Distribution of Strong Ground Motions Recorded during the 21 September 1999 Chi-Chi, Taiwan Earthquake
}

\author{
Jen-Kuang Chung ${ }^{1}$ and Tzay-Chyn Shin ${ }^{1}$ \\ (Manuscript received 4 October 1999, in final form 1 November 1999)
}

\begin{abstract}
The 21 September 1999 Chi-Chi earthquake $\left(M_{L}=7.3\right)$ was the largest inland quake occurred in Taiwan in the past 100 years. According to direct field observations, a significant thrust rupture was occurred along the active Shuangtung fault and Chelungpu fault. From the integrated displacement derived from free-field strong motions around the source area, horizontal displacements over $9 \mathrm{~m}$ and vertical offsets reaching $3.4 \mathrm{~m}$ are obtained at the station TCU068 located nearby the northern section of Chelungpu fault. Based on the field observations of slip distribution over the entire 77-km surface break and the integrated displacement waveforms, we have arrived at the following findings: An obvious small offset at about $3 \mathrm{sec}$ prior to the principal offset is observed at two sites close to the southern part of Shuangtung fault. This small offset is not shown on the other stations. We propose that a relatively small event, probably with a magnitude of about 6.0, occurred about $3 \mathrm{sec}$ before the major rupture, that is located at the Shuangtung fault about $8 \mathrm{~km}$ east of the Chelungpu fault. The induced northward propagating rupture along the Chelungpu fault has reached a maximum permanent offset over $9 \mathrm{~m}$ at the northern section of fault. This northern section of the Chelungpu fault was identified as one of the heaviest damaged areas.
\end{abstract}

(Key words: Chi-Chi earthquake, Fault rupture, Permanent displacement field)

\section{INTRODUCTION}

A major earthquake $\left(M_{L}=7.3\right)$ has occurred near the town Chi-Chi in the Nantou county, Taiwan, at 1:47 a.m. (local time), September 21, 1999. The focal depth is $8 \mathrm{~km}$. The death toll until the end of September has exceeded 2100 and is mounting during the first week after the main shock. This earthquake is the largest inland event in Taiwan in this Century and has

\footnotetext{
${ }^{1}$ Seismology Center, Central Weather Bureau, Taipei, Taiwan, ROC
} 
provided a wealth of digital data for seismology and earthquake engineering because a successful implementation of the six-year Taiwan Strong Motion Instrumentation Program (TSMIP) completed two years ago. It is believed that this big earthquake is intimately related to the recurrent movement of the Shuangtung fault and the Chelungpu fault. The Chelungpu fault is a thrust fault, that has an extension of about $77 \mathrm{~km}$ from Minchien, Nantou in the south to Fengyuan, Taichung to the north, with an almost N-S strike (Chang et al., 1998). According to the direct field investigation, the surface break shows large vertical as well as horizontal displacements along the fault line as a consequence of the Chi-Chi earthquake.

Over thirty free-field strong-motion stations equipped with an A-900 (Teledyne Geotech) or IDS-3602 (Terra Technology) accelerometer are deployed close to the Chelungpu fault by the Central Weather Bureau (CWB) under the TSMIP project, which lasts from 1991 to 1997. From those retrieved near-field accelerograms of this Chi-Chi event, the significant permanent offsets are easily derived by using a simple integration process. These displacement results give the reason why the heaviest damage occurs along the northern section of the Chelungpu fault zone, in complete agreement at the on-site damage investigation provided by many researchers. For such a devastating event, the strong-motion instruments deployed nearby the fault can record the dynamic behavior associated with the rupturing process. This paper shows the displacement field on the both sides along the two faults through a simple integration of the accelerogram data. This result provides direct evidence to geologists and seismologists in the interpretation of faulting process. The rupture characteristics of this seismic source, as it relates to the regional tectonics, can also be reconstructed with this integrated displacement field as an important constraint.

\section{DATA PROCESSING}

For the TSMIP network, each station (either an A-900 or an IDS-3602) consists of a three-component force-balanced accelerometer recorded at a 16-bit resolution and a 96-db dynamic range. The full scale of recording system is $\pm 2 \mathrm{~g}$. The instrument response of acceleration is almost flat from DC to $50 \mathrm{~Hz}$. Basically, the basic specifications of the both instrument types are the same, except the sampling rate. The A-900 is sampled at $200 \mathrm{sps}$, and the IDS-3602 at 250 sps. It is necessary to do some pre-processing, like decoding, time-checking, and baseline correction, on the raw data.

During the first five days after the main shock, some accelerograms recorded in the central Taiwan region are retrieved and are immediately sent to CWB for data processing. To obtain the displacement field, the accelerograms are integrated twice in the frequency domain. Suppose the acceleration is $A(t)$, then it can be transformed into frequency domain as $A(\omega)$ by using the Fourier transform method, where $t$ and $\omega$ represent the time and the angular frequency, respectively. By the integration theorem, the displacement $D(t)$ can be derived from the inverse Fourier transform of $D(\omega)$, which is equal to $-A(\omega) / \omega^{2}$. Obviously, passing over to the frequency domain, the operations are straight-forward. Since all the data used in this paper have very high signal-to-noise ratio, there is no need to apply additional filtering during the integration process. Inevitably, the displacement seismograms still have some long-period 
components caused by the instrumental drift during the time of strong shaking or the digitization problem in the part prior to the event signal. Although the anomaly produces only a small acceleration offset, it can have a noticeable effect on the double integral of the acceleration data (Iwan et al., 1985). In general, the long-period (200 to $400 \mathrm{sec}$ ) trend is obvious and can be easily traced in the integrated displacement waveform, since the record length is over 60 sec that is much longer than the displacement signal. Therefore, we use a sinusoid function to fit the trend and subtract it from the integrated time history to obtain the displacement waveform for measuring the permanent offset.

\section{RESULTS}

Figure 1 is the accelerogram recorded at station TCU068 located at about $8 \mathrm{~km}$ east of Fengyuan. The peak ground accelerations (PGA) in the U-D, N-S, and E-W components are 519 gals, 362 gals, and 502 gals, respectively. The integrated displacements that the long trend is removed are shown in Fig. 2. Obvious ramp-type slip function appears on the displacement waveforms. In general, it is not difficult to estimate the permanent offsets directly from the waveform for such a case. The estimations show that the first major movement is about $451 \mathrm{~cm}$ to up, $776 \mathrm{~cm}$ to north, and $820 \mathrm{~cm}$ to west with a rise time about $4 \sim 5$ seconds. Followed with the first movement, the elastic rebound with $106 \mathrm{~cm}, 266 \mathrm{~cm}$, and $55 \mathrm{~cm}$, respectively, is occurred and lasts about 3 seconds. Therefore, the permanent offset is $345 \mathrm{~cm}$ to up, $510 \mathrm{~cm}$ to north, and $765 \mathrm{~cm}$ to west. This clear observation of the slip function at this large amplitude is perhaps the first time in seismological history. Another station TCU052, located $10 \mathrm{~km}$ south of TCU068, has also recorded extremely large offset, about $340 \mathrm{~cm}$ to up, $550 \mathrm{~cm}$ to north, and $345 \mathrm{~cm}$ to west (Fig. 3). These two stations are both located at northern part of the hanging wall of the Chelungpu thrust fault. On the other hand, one of the stations near southern part of the fault, namely TCU129, has recorded 983 gals (over $1 \mathrm{~g}$ ) in the E-W component of acceleration, which is about two times greater than the PGA recorded at the above two stations. But the horizontal offset on this site is only $50 \mathrm{~cm}$ to south and $110 \mathrm{~cm}$ to east. No obvious offset is estimated in the vertical component. This phenomenon indicates that the slip along the fault nupture is not necessary proportional to the generated acceleration. The effects of the rupture propagation should play an important role in this case. A forthcoming paper will further clarify that point.

The derived offsets at twenty-two CWB's free-field strong-motion stations near the Chelungpu fault and the Shuangtung fault are given in Table 1 and the displacement distribution around the two faults is shown in Fig. 4. The two orthogonal red arrows at each site mean the horizontal N-S and E-W displacements, while the solid and open blue arrows represent upward and downward movements, respectively. The three component displacements for all stations are plotted in the same scale indicated in the figure legend. It is clearly seen that the offsets on the eastern side of Chelungpu thrust fault, the hanging wall, have systematically larger northwestern displacements, which are opposite to the movernents of the western side, the footwall. With the well-known southeast-northwestern regional tectonic compression operative in Taiwan, the offset distribution gives a consistent picture and has explained the major 


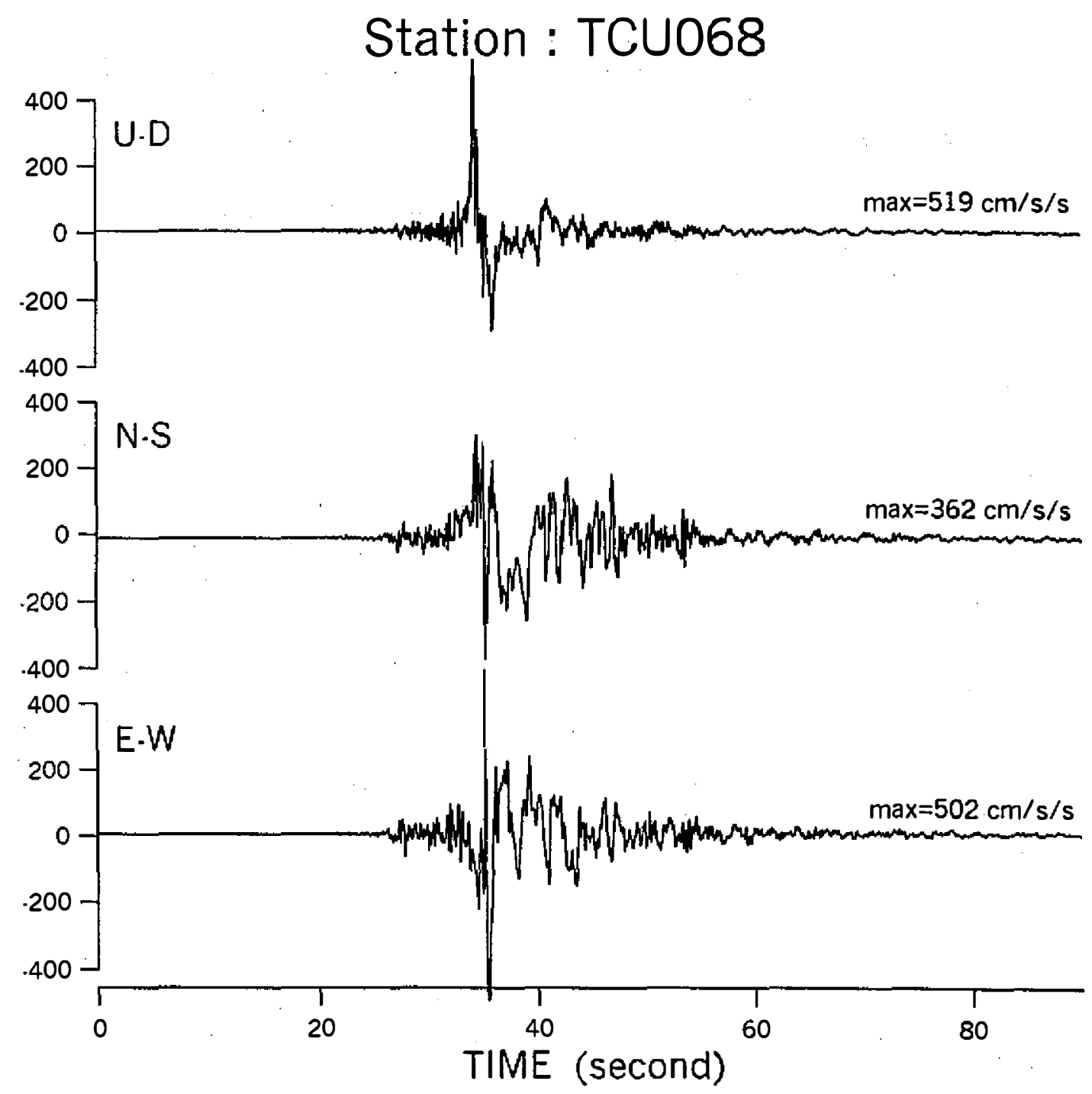

Fig. 1. Accelerogram recorded at the free-field station TCU068.

thrust faulting along the Chelungpu fault during the earthquake. Field geological survey of the surface break also gives the ground truth of this integrated displacement field. The offset decreases to only several centimeters on the sites only $10 \mathrm{~km}$ away from the fault on the footwall side.

For a thrust fault, the ground motion is not expected to be the same on both sides of the fault. Based on simple geometry, it is expected that sites located on the hanging wall will have larger ground motions than sites at the same rupture distance located on the footwall because the hanging-wall sites are closer to a larger area of the source than the footwall sites. However, the two stations, TCU068 and TCU052, with the extreme large offsets should be located 

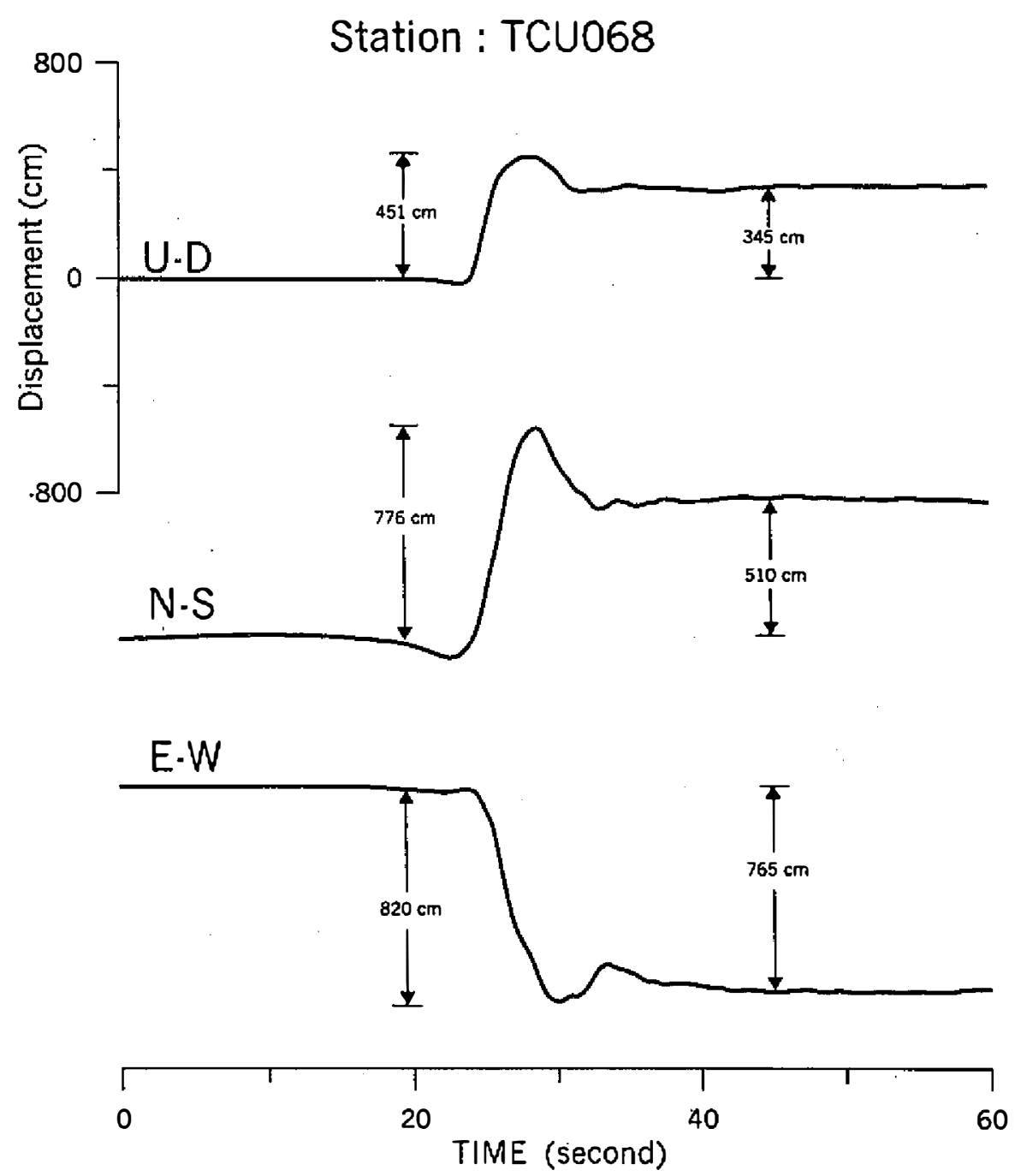

Fig. 2. Integrated displacement waveforms derived from the accelerogram recorded at the free-field station TCU068. The permanent offset for each component is measured directly from the waveform.

on the hanging wall side and are very close to the rupture outcrop of Chelungpu fault. Examining the displacement distribution in the area, the N-S offset seems increase from south to north of the fault zone. This phenomenon implies that the pure thrust rupture propagates and changes from pure thrusting to oblique thrusting with strike-slip component from south toward north, with increasing rupture slip. For the vertical permanent offset distribution, only a small downward slip on the order of about $10 \mathrm{~cm}$ are observed on the footwall sites, while larger uplift can be derived on the hanging-wall sites. The pattern agrees well with the static 


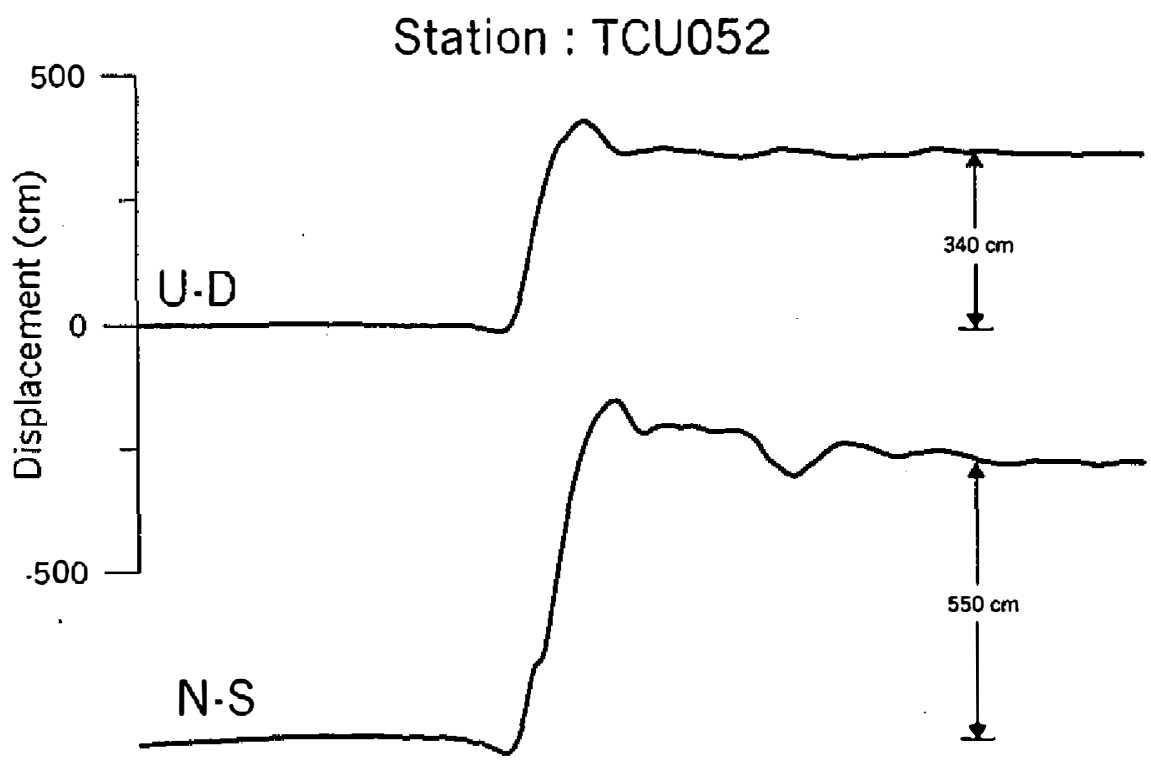

$E \cdot W$

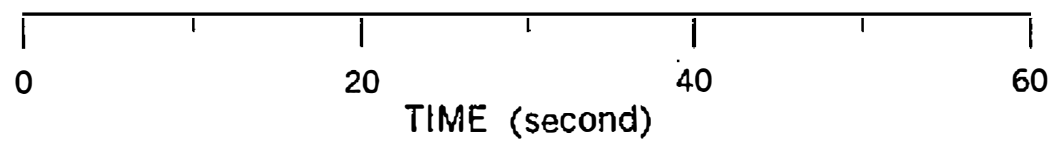

Fig. 3. Integrated displacement waveforms derived from the accelerogram recorded at the free-field station TCU052.

model of the thrust faulting. Some downward slips are also measured at stations located southeast of Shuangtung fault. It is due to the pulling of up-thrusting material that causes the sinking of soft surface sediments under the extension.

\section{DISCUSSION AND CONCLUSION}

The location of the main shock epicenter is at $120.82^{\circ} \mathrm{E}, 23.86^{\circ} \mathrm{N}$, where is about $2 \mathrm{~km}$ the eastern side of the south tip of Shuangtung fault. Figure 5 represents the focal mechanism 
Table 1. The Final Displacements and PGA at Free-field Strong-motion Stations.

\begin{tabular}{|c|c|c|c|c|c|c|c|c|}
\hline \multirow{2}{*}{$\begin{array}{c}\text { Station } \\
\text { Code }\end{array}$} & \multirow{2}{*}{${ }^{\circ} \mathrm{E}$} & \multirow{2}{*}{$\begin{array}{l}\text { Latitude } \\
{ }^{\circ} \mathrm{N}\end{array}$} & \multicolumn{3}{|c|}{ Final displacement $(\mathrm{cm})$} & \multicolumn{3}{|c|}{ PGA (gals) } \\
\hline & & & U-D & $\mathrm{N}-\mathrm{S}$ & E-W & U-D & $\mathrm{N}-\mathrm{S}$ & $\mathrm{E}-\mathrm{W}$ \\
\hline & 120.766 & 24.278 & 345 & 510 & -765 & 519.4 & 361.9 & 50 \\
\hline$\overline{102}$ & 0.721 & .249 & -13 & -58 & 93 & 173.3 & $169.0 \mid$ & \\
\hline J053 & 0.669 & 24.194 & - & -68 & 75 & 120.9 & 132.1 & 2 \\
\hline J052 & 0.740 & .198 & 340 & 550 & -345 & 194.0 & $438.7 \mid$ & $\overline{34 \varepsilon}$ \\
\hline 104 & 0.690 & .1 & - & -55 & 75 & 178.0 & 241.9 & 27. \\
\hline U054 & 120.675 & 24.162 & - & -90 & 60 & 133.0 & $\mid 190.4$ & \\
\hline U082 & 120.676 & 24.148 & - & -50 & 92 & 129.3 & $\mid 182.5$ & 22 \\
\hline Y025 & 120.514 & 23 & - & $|-8|$ & 30 & 169.7 & 152.0 & $15 \varepsilon_{-}$ \\
\hline Y1011 & 20.562 & 23.686 & -1 & -30 & -35 & 162.2 & $390.1 \mid$ & 33 \\
\hline CU067| & 120.720 & 24.092 & -13 & -40 & 140 & 230.6 & 312.7 & 488 \\
\hline TCU065 & 20.691 & 24.059 & $\mid-12$ & -30 & 125 & 257.8 & 563.2 & $\overline{77}$ \\
\hline CHY024 & 20.607 & 23.758 & -10 & -7 & 48 & 141.4 & 162.2 & 27 \\
\hline ГCU072 & 120.849 & 24. & 145 & 225 & -190 & 274.7 & 370.5 & 46. \\
\hline TCU122 & 120.610 & 23.8 & -4 & -16 & 75 & 236.0 & 255.6 & 20 \\
\hline TCU075 & 120.678 & 23.984 & -12 & -16 & 120 & 223.9 & $257.3 \mid$ & 32 \\
\hline TCU074 & 120.962 & 23.961 & -58 & $\overline{132}$ & -190 & 270.2 & 368.4 & 58 \\
\hline TCU076 & 120.676 & 23.908 & $-5 \mid$ & -42 & $\overline{75}$ & 275.4 & 420.0 & $\overline{340}$ \\
\hline TCU129 & 120.684 & 23.878 & -1 & -50 & 110 & 335.0 & 610.8 & 98 \\
\hline TCU089 & 120.857 & 23.904 & -10 & 130 & -175 & 190.2 & 225.3 & 347 \\
\hline TCU078 & 120.846 & 23.812 & -17 & 65 & -110 & 171.0 & 302.5 & $\overline{43}$ \\
\hline CU071 & 120.788 & 23 & 255 & 315 & -250 & 415.5 & 639.0 & $51^{\prime}$ \\
\hline CU120 & 120.613 & 23.980 & -2 & -22 & ro & 166.5 & 193.5 & 22 \\
\hline
\end{tabular}

* The symbol " - ' in U-D displacement indicates that the value is about zero or is difficult to estimate.

** The negative values of final displacement in U-D, N-S, and E-W component represent downward, southward, and westward movement, respectively.

determined from the polarity of $\mathrm{P}$ waves recorded by the CWB short-period seismic network and some strong-motion stations. The solution is with the strike $\mathrm{N} 20^{\circ} \mathrm{E}$, dip $30^{\circ}$, and rake of $85^{\circ}$. It is presumably the rupture plane at its nucleation stage. Figure 6 shows the displacement waveforms recorded at the stations TCU078 and TCU089 located at the eastem side of Shuangtung fault. These two stations are the closest sites from the epicenter. The integrated displacement waveforms show a smaller slip observed at about $3 \mathrm{sec}$ prior to the principal slip pulse. This smaller slip is not observed at the other stations. This phenomenon indicates that a relatively small event, probably with a magnitude of about 6.0 , occurred before the major rupture and is estimated at about $8 \mathrm{~km}$ east of Chelungpu fault. Using the final displacement 


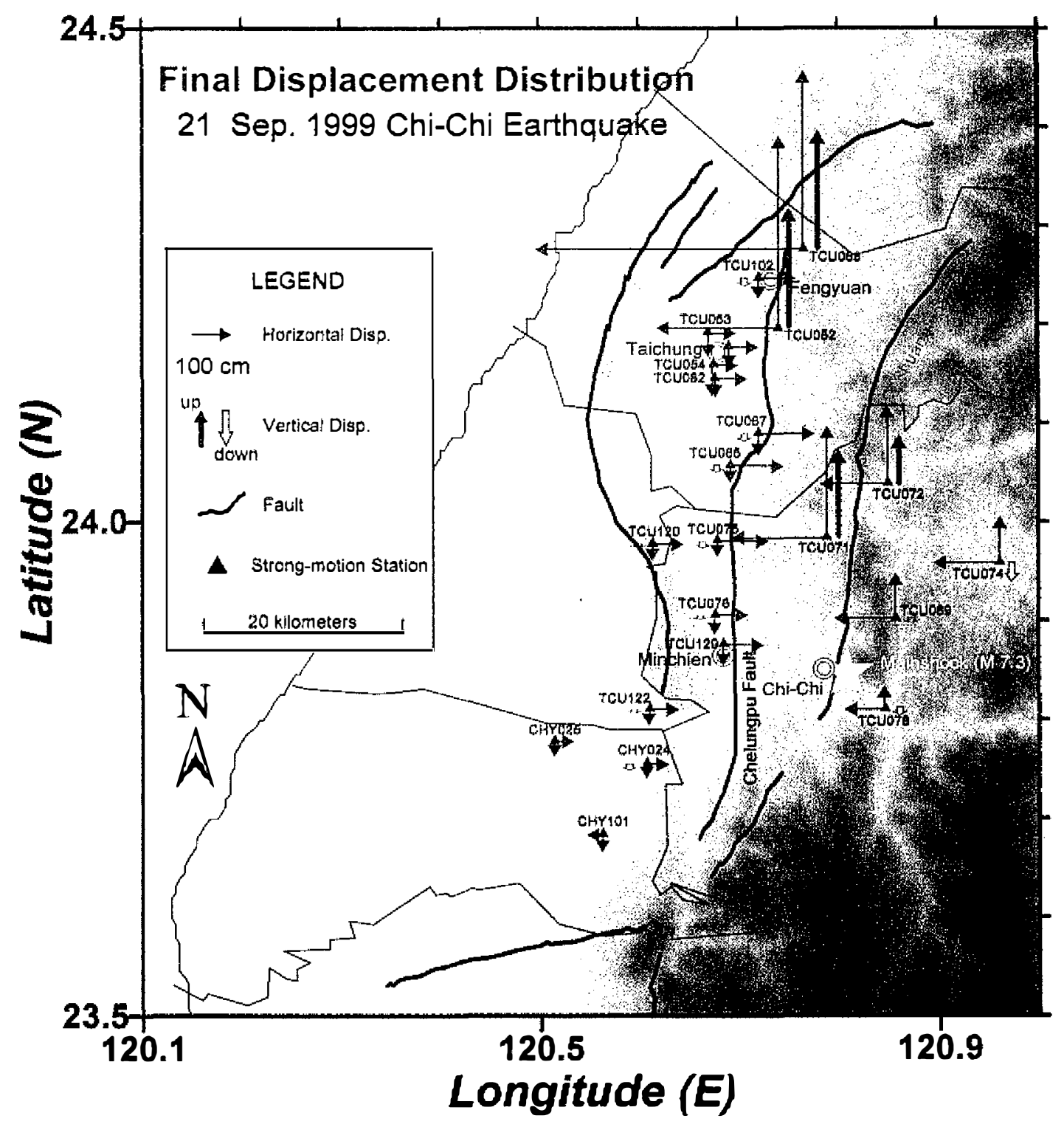

Fig. 4. Final displacement distribution estimated from the free-field stations closed to the Chelungpu fault and the Shuangtung fault. The two orthogonal red arrows at each site mean the horizontal N-S and E-W displacements, while the solid and open blue arrows represent upward and downward displacements, respectively.

distribution observed at the source area, we propose that the Chi-Chi earthquake initiate at the Shuangtung fault and then the major rupture at Chelungpu fault was triggered in about $3 \mathrm{sec}-$ onds. The northward propagating rupture along the Chelungpu fault has reached to a maxi- 
$1999 \cdot 9$ 20 $17: 47: 16.00$

$M L: 7.3$

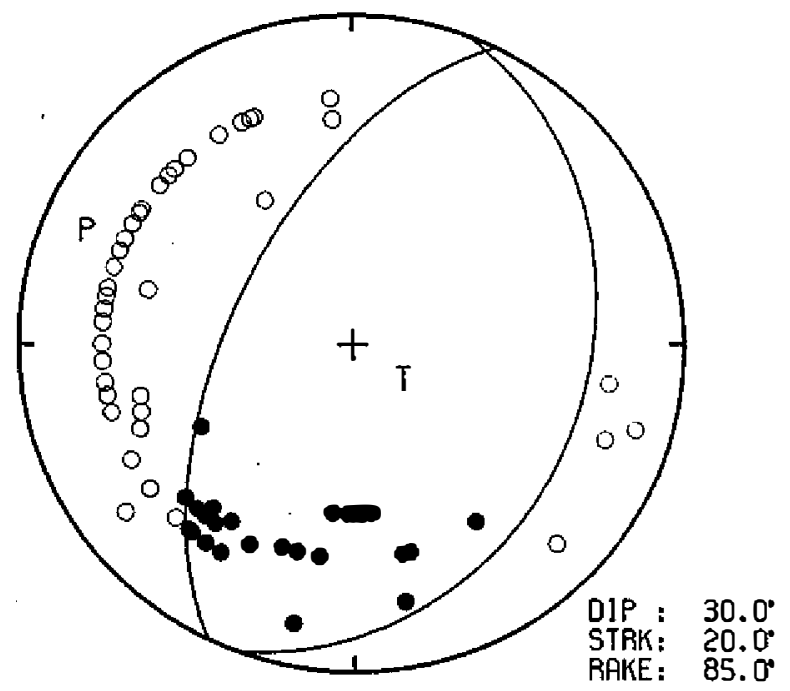

Fig. 5. Fault plane solution of the Chi-Chi main shock.

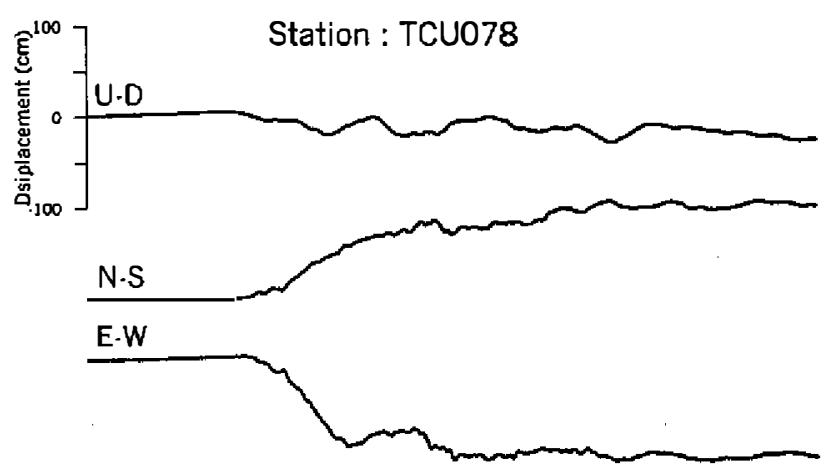

Fig. 6. Integrated displacement waveforms derived from the accelerogram recorded at the freefield station TCU078 and TCU089.

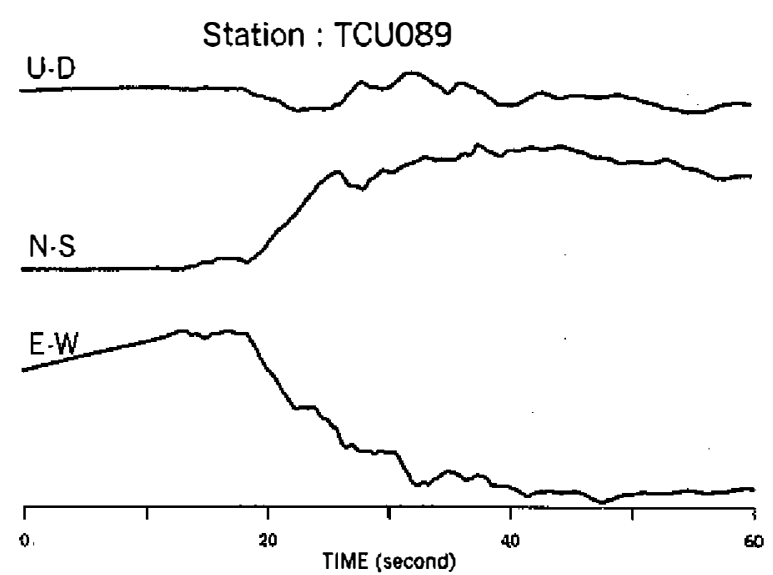


mum offset at the northern section of fault where the free-field strong-motion stations TCU068 and TCU052 are located. The estimation of the slip rate on the northern section of Chelungpu fault is in the range from 100 to $200 \mathrm{~cm} / \mathrm{sec}$ from these two displacement records.

Acknowledgements The authors are indebted to Dr. C. Y. Wang and his assistants of the Institute of Geophysics, National Central University, who took great risk to collect the freefield strong-motion data in the central Taiwan, the source area, immediately after the main shock. They are still working hard in the field when this paper is submitted. The authors wish to thank Dr. T.-L. Teng, Dr. Francis T. Wu and two anonymous reviewers for review and helpful comments. Dr. Y.-M. Wu, C.-H. Chang, and Y.-L. Chen provide many helps for determining the focal mechanism and drawing figures. This research is support by NSC89-2625Z-052-013.

\section{REFERENCES}

Chang, H.-C., C.-W. Lin, M.-M. Chen, and S.-T. Lu, 1998: An introduction to the active faults of Taiwan: Explanatory text of the active fault, Central Geological Survey, MOEA, Taiwan, 103pp.

Iwan, W. D., M. A. Moser, and C.-Y. Peng, 1985: Some observations on strong-motion earthquake measurement using a digital accelerograph. Bull. Seism. Soc. Am., 75, 12251.246. 